\title{
DR-3. AN EFFICIENT SYNTHESIS OF OXAZOLIDINES BY TANDEM RING-OPENING/CLOSING REACTION OF TS-AZIRIDINE USING FORMIC ACID
}

\author{
A. De, A. Majee \\ Department of Chemistry, Visva-Bharati (A Central University), Santiniketan, WB-731235, India \\ E-mail: aramitade91@gmail.com
}

Oxazolidine and its derivatives are very important compounds due to their various pharmacological activities such as antitumor, cytotoxic, anti-inflammatory, analgesic properties and they appear in many natural products like quinocarcin and tetrazomine [1-4]. Synthesis of oxazolidines has been reported from aziridines by the reaction with formic acid and formaldehyde in neat conditions [5]. We have also observed a regio-selective nucleophilic ring opening of aziridines by $\mathrm{HCOOH}$ under same conditions in absence of formaldehyde where the $\mathrm{HCOO}^{-}$ion acts as a nucleophile. In this present method formic acid is not acting as reducing agent as classical organic reactions. We have developed a direct and one-pot synthesis of oxazolidines by addition of formaldehyde in a mixture of aziridines and formic acid in $1: 1: 1$ ratio at $100{ }^{\circ} \mathrm{C}$ temperature without using any catalyst and solvent (Scheme 1).

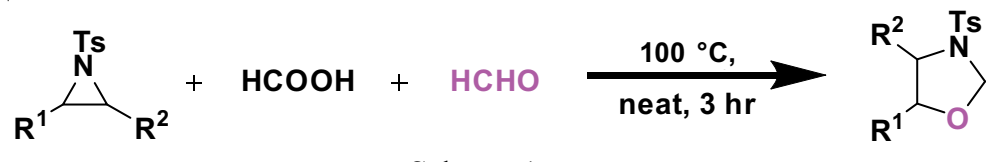

Scheme 1

In absence of formaldehyde the formic acid simply acts on aziridine, which initially activates by the proton and under similar reaction conditions the formate ion on benzyl attack into the activated aziridine gives the ring opening product (Scheme 2).<smiles>[R]C1[Y5]C1[R7]</smiles>

Scheme 2

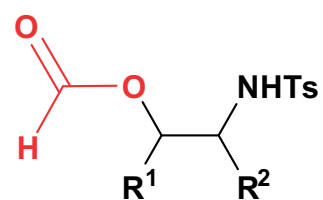

\section{References}

1. Scott J. D., Williams R. M. Total synthesis of (-)-tetrazomine. Determination of the stereochemistry of tetrazomine and the synthesis and biological activity of tetrazomine analogues // J. Am. Chem. Soc. 2002. Vol. 124, № 12. P. 2951-2956.

2. Herberich B., Scott J. D., Williams R. M. Synthesis of a netropsin conjugate of a water-soluble epiquinocarcin analogue: The importance of stereochemistry at nitrogen // Bioorganic Med. Chem. Pergamon. 2000. Vol. 8, № 3. P. 523-532.

3. Yu L., Zhou W., Wang Z. Synthesis and in vitro antibacterial activity of oxazolidine LBM-415 analogs as peptide deformylase inhibitors // Bioorganic Med. Chem. Lett. Pergamon. 2011. Vol. 21, № 5. P. 1541-1544.

4. Gudaprthi V., Bharathi K. O. G. Synthesis, Characterisation and Cardiac Activity of Some Novel2,3-Substituted4-phenyl-1,3-oxazolidine Derivatives // Asian Journal of Chemistry. 2011. Vol. 23, № 2. P. 765-769.

5. Wolf C., Xu H. Asymmetric catalysis with chiral oxazolidine ligands // Chem. Commun. The Royal Society of Chemistry. 2011. Vol. 47, № 12. P. 3339-3350. 